\title{
ON THE EVOLUTION OF MORALITY AND RELIGION: A RESPONSE TO LEE CRONK
}

\author{
by Roy A. Rappaport
}

\begin{abstract}
Issue is taken with Dawkins and Krebs's (1978) conception of communication as being by nature manipulative and with Cronk's proposals concerning the evolution of morality, both of which are grounded in evolutionary biology. An alternative view, which recognizes that which humanity has in common with other species but which emphasizes humanity's distinctiveness, is offered to account for religion and morality.
\end{abstract}

Keywords: evolution; falsehood; manipulation; morality; ritual; truth.

Any understanding of morality's evolution must recognize what humans have in common with other living things. The binomial Homo sapiens, after all, or rather first of all, denotes a species of organisms no less animal than the creatures designated by Didelphis marsupialis or Mantis religiosa. Humans are as possessed of physiological needs and reproductive imperatives as opossums or praying mantises, but it is one thing to recognize humanity's animal nature and another to agree that reference to it is sufficient to account for, or to understand, human phenomena, including morality, in full or in general. I do not wish to misrepresent the positions of Lee Cronk or others working within evolutionary biological paradigms, but that does seem to me to be what they are attempting to do.

At the same time that we recognize what humanity has in common with all other species, we must recognize what distinguishes it from all of them and what, in distinguishing it, has changed the nature of evolution itself. The attempts of evolutionary biology to account for morality, both Lee Cronk's proposals and those that he reviews and criticizes, fail, in my view, to give humanity's distinctiveness its due

Roy Rappaport, Walgreen Professor for the Study of Human Understanding, is a member of the Anthropology Department and Director of the Program on Studies in Religion at the University of Michigan, Ann Arbor, MI 48104.

[Zygon, vol. 29, no. 3 (September 1994).]

(C) 1994 by the Joint Publication Board of Zygon. ISSN 0591-2385 
and therefore fail to provide or even to promise a satisfactory account of morality's emergence.

In the first section of his essay, Cronk reviews several evolutionary theories concerning the grounds of morality with a view to criticizing them subsequently in light of recent ethological theorizing concerning signaling. Because my reactions to these formulations differ from his, I will comment on them briefly before registering my agreements and disagreements with Cronk himself, during the course of which I will offer alternative views of morality and religion.

\section{EVOLUTIONARY THEORIES OF MORALITY}

First, the economistic rationality that is assumed by at least some individual benefit models strikes me as unreal if the proposal is that actual calculation, conscious or unconscious, of costs and benefits guide all or most individuals' interactions with their fellows. It could, however, be argued, as Richard Alexander (1985) may come close to doing, that moral systems go far to obviate the necessity for such calculations in all but doubtful cases. If this is so, such systems of moral discourse, in addition to enhancing the internal cohesiveness of social groups and thus enhancing their ability to compete with others, would be economical with respect to individual decisionmaking capacities, allowing them to be used to consider other things, and might well reduce anxiety to boot.

The notion of "innate predispositions to cooperate" smells faintly of sociological phlogiston. Assertions of such predispositions are dubious if they claim direct genetic determination but, just as damaging, are indubitable if the assertion is that humans (at least "normal" humans) are genetically capable of internalizing moral sentiments. That they are is amply demonstrated by the fact that they do. In sum, the notion of innate predispositions doesn't seem to amount to much.

The heart of Cronk's critique of these approaches is a general attack on the primacy of cooperation, an attack implicit in the assertion, originating with Dawkins and Krebs (1978), "that signals may best be seen as attempts to manipulate others rather than to inform them" (emphases mine).

Serious problems beset this proposal. First, there is the matter of what is to be counted as manipulation. It could, for instance, be argued that all calls for cooperation are manipulative, in which case manipulation is coextensive with social action, social action coextensive with social life, and social life ubiquitous among sexually repro- 
ducing organisms (inasmuch as sexual reproduction requires some degree of cooperation between males and females). Such a broad definition of manipulation dilutes it to such weakness that it becomes trivial, too true to be good.

If, on the other hand, "manipulation" is given a more restrictive meaning, something close to a logical flaw becomes evident, as Cronk and others he cites (for example, Harper 1991) may recognize. Receivers of messages cannot be manipulated unless they have a substantial degree of confidence in the information they receive. Such confidence is most efficiently and effectively established by being honest all, or almost all, of the time: effective manipulativeness is dependent on being reliably informative. Furthermore, if, as is probable, the preponderance of messages at most times and in most places is transmitted between closely related (socially or genetically) individuals, the interests of senders and receivers are likely to be common or complementary, and the transmissions are, therefore, likely to be honestly informative. All of this is to say that signals are not, and cannot be, "best seen" as manipulative rather than informative. To so see them furthermore falls into the fallacy of elevating the defining characteristic of a subclass of signals (manipulative signals) to the status of an essential property of signals generally. Be this as it may, signals, at least those transmitted among members of a social group, cannot ever be effectively manipulative in anything other than a trivial sense unless they are usually, or even almost always, honestly informative. Dawkins and Krebs's assertion $(1978,309)$, "If information is shared at all it is likely to be false information" strikes me as self-contradictory (we may have here an instance or variation of the Cretan liar paradox) or even absurd as a generalization about transmissions other than those between antagonists (as in agonistic displays), enemies, or predators and prey.

A similar logical problem vexes the assertion that "noncooperative signals," that is, those transmitted by senders to receivers with whom they share no or few interests, will evolve to be conspicuous and repetitive. If senders and receivers are conspecifics, it is plausible to assume that what senders know about transmitting and its tricks would inform and guide their alternate role, which is receiving. We would expect that they would quickly learn that the more conspicuous and repetitive the signal, the less it can be trusted, and the less effectively manipulative it therefore would or could be. To be effectively manipulative, messages must resemble honest ones. 


\section{Zygon}

Dawkins and Krebs's conclusion concerning the prevalence of false information derives from their definition of communication, a definition which I take to be so deformed as to be teratoid, offered earlier in the same essay $(1978,283)$, and repeated by Cronk. "Communication," they tell us, "is said to occur when an animal, the actor, does something which appears to be the result of selection to influence the sense organs of another animal, the reactor, so that the reactor's behavior changes to the advantage of the actor." This definition is a logical and methodological disaster. It builds arbitrary and dubious assertions concerning origins, motives, and outcomes into the conception of a phenomenon more usefully and more soundly defined in a simpler and more straightforward way. Even if one agreed with Dawkins and Krebs's view of communication, it would be better to say that communication occurs when a sender transmits information to a receiver. Whether or not the receivers actually receive the information, how that information is interpreted, what the outcome of the transmission may be, whether the mode of transmission or the message is to be accounted for by natural selection, whether the message is honest, duplicitious, or manipulative, are all separate questions the answers to which bear upon the validity of the assertion of communication's essential manipulativeness. It is obvious that a transmitter's motives may be manipulative (that is, turning the reactor's behavior to the advantage of the actor), but it is logically inadmissible to take such a motive and its substantive effects to be definitive of communication if those motives and effects are to account for communication.

There is something else. The streetwise sort of cynicism that Dawkins and Krebs's definition indulges (it is as if they are looking over the world's shoulder to wink knowingly at the readers, wising them up to the big scam) is much too easy. It misidentifies real problems troubling human comunication and produces a superficial, incomplete, and distorted view of human nature. Although it is not their intention or Cronk's, they have revealed something deeper and more ominous here. If humans act, and can only act, in terms of meanings they or their ancestors have constructed, it is reasonable to argue that the assumption of this world's falsity will lead to actions that will increase that falsity. If one assumes that all messages one receives are manipulative, one's transmissions will become increasingly manipulative. In addition to being logically fallacious and empirically erroneous, I find the definition socially dangerous and morally repugnant. 


\section{Problems in Human COMMUNICATION}

I will now turn to what I take to be problems intrinsic to communication and set them in a larger context at the outset. To state, as I have, that it is logically fallacious and empirically erroneous or trivial to define communication as essentially manipulative is not to deny that manipulation, deceit, and downright falsehood often afflict communication. To the extent that the transmission of signals is not "under the control of independently specifiable external stimuli and internal ... states" (Marshall 1970) but is in some degree under the conscious control of the transmitter, the transmitter may be in a position at least to refrain from transmitting signals that would jeopardize its health, safety, reproductive success, or whatever. This is to say that the possibility of manipulation and even of deceit are vices intrinsic to the virtues of the communication systems of a very large range of species. Deception, which includes such phenomena as genetic mimicry, is yet more widespread in the animal and even the plant world. Downright deceitfulness which, I have argued elsewhere (1979b), is a class of deceptions characterized not only by an intention to mislead to the disadvantage of the misled but by a violation of the trust that is in some degree definitive of all communities (which are, by etymological association, groups or categories of individuals bound together by shared systems of communication) is widespread among higher primates.

Language, properly so-called, comprises systems of discourse based on grammar and symbols (in Charles Sanders Peirce's sense of symbols, that is, signs only conventionally related to their significata [Peirce 1960]). Such systems, used only by humans, raise new possibilities for falsehood. This statement requires some expansion.

When signs are not intrinsic, but only conventionally related to their significata, they can occur in the absence of their significata, and their potential significata can be the case without being signaled. This frees communication from its confinement to the here and now and thus allows it to report on the past and the distant and to predict, plan, and make promises for the future. Yet more radically, it frees the powers of conception not only from the here and now but also from the concrete altogether and thus enables them to speculate on, and to communicate about, the possible, the impossible, the desirable, the moral, and the imaginary. The advantages of such capacities are patent, and they must have been strongly selected for, but these self-same capacities also make possible the "true lie," a form of falsehood much more elaborate and dangerous than the 
ephemeral deceptions of which apes are capable. True lies, which employ language's ability to escape from the present and visible, facilitate by magnitudes the perpetration of duplicity, manipulation, and deceit.

As Cronk, following Nietzsche and others, correctly observes, moral proclamations can be manipulative and deceitful. But to say that they, and transmissions in general, can be and often are in some way false falls far short of saying that they are generally or necessarily so. The assertion that communication is essentially manipulative if not deceitful seems to me to misidentify a problem sufficiently serious to subvert any community whose social life is based upon language, which is to say all human communities. If the system of communication accommodates and even facilitates lying, how are receivers of information to be assured that the information they receive is sufficiently reliable to act upon? Lack of trust in received information may be just as endangering to the functioning of a community, and thus to its individual members, as the falsehoods that the received information may carry. If individuals must ponder the truthfulness of all, most, or even very many of the messages they receive before they act upon them, the orderliness of social life is likely to break down. What were called "credibility gaps" during the Vietnam war years are seriously disruptive.

There is a further and deeper problem that language creates for human social systems. It is the problem not merely of the veracity of messages concerning current states of affairs, but the metaphysical or ontological problem of verity, of the grounds of existence. This is more a problem of grammar than it is of symbol. If a language has sufficient grammar and lexicon for its users to say and think "YHVH is God and Marduk is not," it is possible to think, say, and act upon the converse. The imagination of alternative orders is an ineluctable product of language and, at the same time that this imaginative capacity provides our species with unparalleled adaptive flexibility, it challenges the species with new possibilities for disruption. The ways in which religious discourse may ameliorate these problems will be discussed later. I will only note here that Martin Buber (1952) took lie and alternative to be the roots of all human evil.

\section{MORAL CHOICES AND INDIVIDUAL BENEFITS}

Cynicism, has its uses and may even, in limited doses, be a good thing, but it is proverbially possible to have too much of most good things. This brings me to more specific points of disagreement with Cronk including, first of all, his discussion of the problem that care 
of elderly parents seems to make for evolutionary theories of morality.

First, I don't think that these problems should be very difficult even in those theories' own restrictive terms. For one thing, old folks, who in premodern societies are usually few and often active until close to the end, pay their own ways. It has often been noted that they are repositories of valuable and even crucial information and of ritual knowledge as well, that they often take care of young children, that they look after the house or camp, and so on. In line with individual-benefit models, it should also be kept in mind that significant third parties, especially their own children, are often watching how people in their prime treat their declining parents. These children may well model their treatment of their parents in their declining years on the ways they saw their parents treat their grandparents.

Notions of manipulativeness, even to this degree, which could as well be seen as indirect cooperation, needn't be invoked to account for why it is said in India (to the extent it is) that in the absence of parental property "children do not look after their parents well," or why rich men feel more secure about their children's support of them in old age than do poor men. When parents are without property, their children are likely to be without property, and poor men may not be so much cynical about the magnanimity of their children as pessimistic about the ability of those children, likely to be as poor as they are, to take care of them.

But the care of elderly parents raises deeper questions about evolutionary theories of morality. It challenges the central place they give to rationality itself. I would suggest that a concomitant of effective parental care of children is deep emotional connection. Human parents usually-dare I say it-love their children, who usually reciprocate in kind or in complement. Such two-way bonding seems to be humanly universal and, although often sorely strained, it generally persists throughout life, normally becoming, if the parents live long enough, inverted, with children eventually assuming the roles of care-givers and protectors to their parents. The basis of care of the aged, this is to say, is affective rather than rational, and it is established in childhood. If parental love of and care for children is crucial to the development of normal human beings, then love of, and eventually care for, aged parents may well be its concomitant and no less an aspect of normal human nature. Some people do, as we all know, abuse or forsake their aged parents (often, perhaps, in reaction to their parents' failures to elicit their love when they were children) and selfish considerations may enter into care-giving of all 
sorts. But we are told much less than the whole truth about parentchild relationships if we take calculations of individual self-interest to be at their heart.

\section{RITUALS AS RELIGIOUS COMMUNICATION}

The manipulative approach to signals may, as Cronk proposes, shed some light on the moralistic contents of some religious discourse, but it also may so shadow that discourse as to obscure its full character. It is undeniably true that religions have often been used by elites for purposes of social control, but it is important to emphasize, and I think Cronk would agree, although he is not explicit on this point, that this is not an adequate characterization of religion in general or in essence, nor can social control by elites account for the origins of religion. Religion, it is plausible to argue, although direct evidence is lacking, is as old as humanity, which is to say as old as language, and as such, it is further plausible to argue, it appeared millennia, probably many millennia, before anything that could properly be called an "elite" developed. There were no real elites in the many near-contemporary, near-egalitarian societies observed by anthropologists, and in societies in which such elites are present, it would be too simple and too crass to view religions as, simply, tools of rulers.

Further problems trouble Cronk's discussion of religious discourse. He proposes that "the loudest and most elaborate religious moral proclamations" are instances "in which the signaler is attempting to get the receiver to act in a way that benefits the signaler and may harm the receiver." Cynicism again leads us to understandings that are at best shallow and probably wrong. I have little or no sympathy for much of what many religions do, especially in their attempts to spread their word to unbelievers, but I will at least grant to most missionaries that they usually think that they are doing their converts some good, even the ultimate good of saving their immortal souls. That they may be doing them terrible injury does not make their signals duplicitous, manipulative, or noncooperative, just (with possibly the best will in the world) tragically wrong.

There is a much more subtle and profound difficulty. Cronk's formulation seems to assume that, in the case of "religious moral proclamations," as in the case of ordinary profane communication, the signalers and the receivers are separate and distinct living persons. This is not primarily the case in the most typical and important form of religious communication, ritual. Elsewhere (1979a, 175) I have defined ritual as the performance of more or less invariant sequences 
of formal acts and utterances not [entirely] encoded by the performers. This definition seems to cover what students of animal behavior as well as religion mean by the term. I have argued (1979a; 1979b), however, that when expressions from languages are subordinated to ritual's form, concepts basic to society and religion-social contract, morality, a paradigm of creation, the concept of the sacred, the notion of the eternal, and the sense of the divine-are all created. More to the point here, I further argue that the most significant receivers of the messages encoded in ritual are the transmitters themselves, and the messages they transmit to themselves are not trivial. It follows that if the transmitters of a ritual's messages are its most significant receivers, the characterization of its messages as the manipulations of social elites is always inadequate and often wrong.

The matter is in its nature involuted. The simplified account that follows will have to suffice (a fuller account is offered in Rappaport 1979a).

To perform a ritual, by definition a more or less invariant sequence of formal acts and utterances largely specified by agencies other than the performers, is perforce to conform to that ritual's order. As such, recognition of authority is intrinsic to the performance of all rituals, but the relationship of performers to the liturgical orders they perform is more intimate and binding than terms like "authority" and "conformity" connote. The orders encoded in ritual are enlivened or realized-made real-only when those acts are performed and those utterances voiced. The relationship of the act of performance to the order performed-that the act ever again enlivens the order-also establishes the relationship of the performers to the orders they realize. They are not merely transmitting messages they find encoded in the ritual's canon. They are participating in, that is to say becoming parts of, the orders to which their own bodies and breath give life. For participants to reject an order that their own participation enlivens while they are themselves parts of that order would be self-contradictory and therefore impossible. The message that the performers transmit to themselves, and sometimes to others as well, therefore includes not only the substance of the canons they perform - that the Lord is one or three or (as the Lakota would have it) sixteen, or that they shall not bear false witness, or that they shall honor their fathers and mothers. Each participant also indicates to himself or herself, and to other members of the congregation as well, that he or she accepts the order encoded in the ritual in which he or she is participating.

This assertion is, on the face of it, dubious, so I hasten to make clear that the ritual acts of acceptance do not necessarily imply belief. Belief is a private state knowable, if at all, subjectively. Acceptance, in 
contrast, is a public act, visible to both the acceptor and to others. Belief is one, but not the only reason, to accept. I further hasten to add, that acceptance of an order does not guarantee that its dictates-prohibitions on incest or murder, commands to observe the Sabbath-will be honored. But violations of such commandments do not abrogate their acceptance. A ritual act of acceptance establishes an obligation to abide by the terms of the accepted order. It is, of course, obvious that people can and sometimes do violate their obligations, but is further obvious that such violations do not render the violated obligations null and void. (Less obvious, perhaps, there can be no violation of obligation if there is no obligation to violate, and some philosophers [for example, Searle 1969] propose that there is no obligation in the absence of acceptance.)

Note that violation of obligation is always and everywhere regarded as immoral and may well be that which is common to, or even definitive of, all acts so regarded. (Homicide, for instance, is not always immoral. It is killing someone you are obligated not to kill that turns homicide into an immoral act called murder.) I will only note in passing that the act of acceptance as described here is not necessarily "expensive" in any sense of the word, but it is impossible to fake because participation in the ritual ipso facto brings the obligation into being publicly, regardless of the participant's (private) state of mind. He may be insincere, but his insincerity does not let him off obligation's hook. Insincerity is, in fact, rendered irrelevant and even harmless because the public act of ritual acceptance is, in J. L. Austin's (1962) terms, "performative."

This account suggests a possible, or even probable, ground for morality and social contract, and thus for society, in religious ritual. Ritual is capable of establishing society's conventions and its binding rules of conduct in the absence of discrete living authorities able to command the performance of others. In a good many societies, for instance, traditional hunting and gathering societies and in many tribal horticultural societies as well, it does just that. It could, perhaps, be argued that the performers are being manipulated by the imaginary beings that may be invoked in some rituals, not quite as outlandish a suggestion as it sounds, given the powers attributed to spirits, gods, and dead ancestors, and I will return to a related notion later. But, if there is any interest in preserving the notion of manipulation, it may be more plausible to view participants, in joining together in ritual, to be coordinating their separate selves into a congregation and, as such, manipulating themselves into establishing and reestablishing community and into establishing and reestablishing rules which each of them obligates himself or herself to honor. 
This account, it is obvious, rejects simple notions of religion and morality as, in their essence, instruments employed by elites to control others while recognizing that religion can be and is used exploitively and oppressively in some societies. Elsewhere (1979b; 1984, 237), I have argued that the exploitive use of religion is roughly correlated with sociocultural evolution.

\section{SANCTIFICATION OF THE SOCIAL GOOD}

Ritual participation does more than accept whatever is encoded in the ritual's canon. It also sanctifies it, which is to say makes it true. We return here to the amelioration of problems generated by lie and alternative. In earlier works $(1979 a ; 1979 b)$, I have defined sanctity as the quality of unquestionableness imputed by congregations to certain postulates which are, in their nature, objectively unverifiable and absolutely unfalsifiable. These expressions, which I call "Ultimate Sacred Postulates," include such sentences as "The Lord Our God, the Lord Is One," and "There is no god but God and Mohammed Is His Prophet." This account takes sanctity to be a quality of discourse and not of the objects of discourse. In this usage, pronouncements of, for instance, Jesus' divinity in the Mass and in the Gospels are sacred. Jesus' possible or actual divinity is another matter.

Sanctity has its apparent font in ultimate sacred postulates, but it flows from them throughout bodies of social discourse to a wide range of other expressions, including those legitimizing authorities-for example, "Charles, the most Pious Augustus, is crowned by God great and peacekeeping Emperor"; those certifying testimony and oaths, "I swear to tell the truth"; and all sorts of moral dicta and commandments against lying, against murder, against incest, for charity, for valor, for meekness, for honesty. Sanctification, this is to say, escapes from ritual and pervades the general discourse of society. As such, it ameliorates the problems attending lying (for which there could not and probably should not, be any absolute cure) and reduces problems attending alternative. In the community's ritual, the divinity of $\mathrm{YHVH}$, and not Marduk, or vice versa, is accepted as unquestionable, that is to say, it is made absolutely true.

Such truths are fabrications, but they are not for that reason false. They are a subclass of the more general class that Bateson (1951) long ago labeled "truths the validity of which is a function of belief." I prefer to call them "truths the validity of which is a function of their acceptance." They are truths in a sense similar to the sense that it is true that "cat" means cat. They are both fabrications, as are all conventions, but they are none the less true for that. Ultimate sacred 
postulates by this account are not simply one subclass of an array of fabricated truths. They constitute the foundation of the other expressions and institutions whose truth, propriety, morality, or legitimacy they sanctify.

I have asserted, in effect, that sanctity is a product of ritual. In this abbreviated account I cannot do more than note that the unquestionableness which defines the sacred stands on three elements or aspects of ritual. The first, the act of acceptance intrinsic to conformity to an invariant order encoded by others constitutes an agreement not to question. The second, also contingent on invariance, rests on information theory. Information in the technical sense is that which reduces uncertainty. To the extent a ritual order is invariant, its performance is devoid of information. But to say that it is informationless is not to say that it is meaningless because the meaning of informationlessness is certainty (Wallace 1966). This certainty is the second ground of sanctity's unquestionableness. The third is the nondiscursive, emotional, numinous experience that often accompanies ritual performances. These feelings are not merely unfalsifiable but seem undeniable. Thus, the unfalsifiable supported by the undeniable yields the unquestionable, which transforms the dubious, the arbitrary, and the conventional into the apparently correct, the necessary, and the natural. This is the heart of religion and the foundation on which stand the rules, understandings, and institutions constituting human communities. Given language's problems, it is plausible to suppose that this structure emerged with language in some sort of dialectic process. As such, it was an intrinsic and indispensable element in humanity's emergence from its prelinguistic forebears. It constitutes humanity's particular form of sociality which has been no less part of human nature than the selfishness that sociobiologists emphasize or even celebrate.

Every evolutionary advance reveals or creates new problems as it ameliorates or solves older ones, and it is important to recognize that this is as true of sanctity as it is of the language whose problems sanctity addresses. The vulnerability of religion to be bent to the will of oppressors has long been known. When its discourse promises heaven but delivers oppression, its ultimate truths themselves become false. They become the special form of lie that I have elsewhere (1979b) called "diabolical."

\section{THE NATURE AND FORM OF RITUAL COMMUNICATION}

I commend Cronk's attention to the comparative repetitiveness of the ritual orders of different societies. This is a subject that has 
received little attention from scholars of ritual. I would, however, suggest that the category "repetitiveness" is not sufficiently refined to take us very far. What he seems to mean by the term is the frequency with which rituals are performed, but there are other dimensions that should be considered along with frequency, namely, the length of individual rituals and the degree of repetitiveness internal to them.

I myself have addressed matters of ritual frequency and length in the pages of this journal fairly recently (March 1992). To abbreviate that discussion, I suggested (without sufficient evidence, I admit) that the frequency of ritual performances may be related to the degree to which a ritual order represents an attempt not only to regulate ordinary behavior but to penetrate to the motivational, cognitive, and affective grounds of that behavior. This may, in turn, be related to the degree to which the moral dicta encoded or implicit in the ritual order and its performance are vulnerable to violations motivated by internal drives, the temptations of daily life, or the absence of other means for dealing with them. We may think here of cloistered Catholic clergy who daily participate not only in the Mass but in the eight additional rituals constituting the Offices. This extraordinary frequency may be related to the austerity of restrictions on their sexual behavior.

The frequency of ritual performances by Orthodox Jews may be related to the maintenance of social boundaries in the larger societies in which they are minorities. Such frequencies may root burdensome moral dicta so deeply in the psyche that they come to seem "second nature," that is, to seem natural rather than merely moral, and as such very difficult to renounce.

In contrast, communitywide rituals among the Maring people, among whom I have lived in New Guinea, are not so much engaged in the regulation of daily behavior as they are with such political processes as transitions from peace to war and back again. As such, they occur very infrequently. It is important in this regard to note that the Maring are without authorities, such as chiefs, who can command anyone else to do anything - that authority is vested in ritual cycles, and that ritual constitutes the primary means for defining and uniting communities and for effecting transitions in their states (Rappaport 1984).

As far as length of rituals is concerned, it is plausible to suppose that alterations of consciousness are encouraged by intense and lengthy rituals. To put it in the converse, the length of rituals could be related to the profundity of the social and psychic transformations they are supposed to achieve. Longer rituals allow fuller development 
of the peculiar characteristics distinguishing ritual time from everyday life. We would, on this account, expect rites of passage in societies with radically differentiated ontogenetic statuses to be long. There may, of course, be alternatives to length in reaching psychic depths, like drugs or pain. In Australian societies in which ontogenetic status differences are substantial, rites of passage are very long and very painful.

I hasten to note that these and other suggestions I have made in this do not contradict Cronk's proposal that the use of ritual by elites to manipulate subordinates is facilitated by high frequency and that such use and such frequency is associated with complexity of social organization. I do, however, suggest that his proposal addresses a small part of a more complex phenomenon for which manipulativeness does not provide an adequate account.

\section{SOCIAL MANIPULATION AND RELIGIOUS DISCOURSE}

On a more general level, it may be that a good many, or even most, cultural anthropologists do not pay sufficient attention to humanity's organic nature but, more to the point here, it seems to me that sociobiological approaches to such uniquely human phenomena as religion have underestimated, to say the least, humanity's distinctiveness. Recognizing that claims for human uniqueness may bear uncomfortable resemblance to theological claims that place us just below the angels, I nevertheless assert, not at all originally, that language and the conceptions it makes possible do establish an epochal distinction between humanity and the rest of nature. Leslie White, the founder of the University of Michigan's anthropology department, used to say that the emergence of the symbol, a term he used as shorthand for language, was the most radical development in the evolution of evolution itself since life first appeared. If this was an exaggeration, it may not have been much of one. A quibbler could argue that language's appearance was no more important than the appearance of sex. Sex laid the groundwork of sociability, requiring as it does cooperation for reproduction, but it only facilitated the recombination of an already existent genetic form of information. Language, in contrast, brought into being a new and virtually unprecedented class of information, namely, that which is symbolically encoded, and the world has not been the same since. It has become as full of such socially and symbolically encoded fabrications as truth, honor, honesty, generosity, God, democracy, divine right, heaven, hell, mana, taboo, and sanctity as it is full of trees and rocks and rain. 
These conceptions do not simply reflect or approximate a separately existing world but participate in that world's creation. It is, furthermore, in terms of such conceptions, no less than in consideration of trees and rocks and rain, that humans operate, not only in their relations with each other, but in interactions with the ecosystems which, ever since the emergence of plant cultivation ten thousand or so years ago, they have increasingly come to dominate and have increasingly been able to transform, not always-perhaps not even usually-for the better.

It may conform to this account to say that language is central to the adaptive apparatus of the species, but such a view is inadequate as a full characterization of the relationship of language to language users. Language must have emerged as a product of natural selection. Nevertheless, we are, I believe, confronted here with something unprecedented. If it is the case, as I have asserted, that humans act, and can only act in terms of meanings and understandings that they or their ancestors have conceived and enacted into being, then they are as much in the service of those conceptions as those conceptions are parts of their adaptations. This is to say that there has been an inversion, or partial inversion, during the course of humanity's evolution of the relationship of the adaptive apparatus, language, to the adapting species, Homo sapiens. To argue that all of the conceptions involved in this revolution enhance the survival chances or inclusive fitness of individuals in their possession is not credible.

The implications are several. For one thing, the extent to which such concepts as kin selection can account for human institutions and human behavior is limited. For another, and related, whatever the case may be among other species, group selection (in the sense of selection for the perpetuation of traits tending to contribute positively to the persistence of the groups in which they occur but negatively to the survival and reproduction of individuals in their possession) is not only possible among humans but of great importance in human evolution. All that is needed to make it possible are devices that lead individuals to separate their conceptions of well-being or self-interest from their own biological survival. Notions like God, heaven, hell, heroism, honor, shame, democracy, fatherland, inculcated so deeply through enculturation and ritual as to seem factual, natural, or sacred, do very nicely. That actions guided by and preservative of these conceptions and values have often required what Memorial Day orators are wont to call "the Supreme Sacrifice" hardly needs to be said. Postulates concerning the unitary or triune nature of God are among those for whom countless individuals have lost their lives, and so are such heroic declamations as "Death before Dishonor." 
It is worth noting a problematic aspect of the sacrifices that such conceptions encourage. From a strictly sociobiological perspective, they may seem gratuitous or altruistic, especially since it cannot be seriously argued that such behavior enhances inclusive fitness. The self-sacrificers may not, however, be guided by altruistic motives but by the self-serving intention of gaining places in paradise.

Cronk recognizes the degree to which religious discourse can lead people to act in ways that seem counter to their material and biological self-interest, but he, citing Campbell (1991), seems to take such notions to be characteristic of, or even peculiar to, archaic, and perhaps other, states. He therefore interprets them as instruments by which elites manipulate masses. That religion may be degraded to the status of authority's instrument in some state-organized societies is undeniable-at least I myself have so argued elsewhere (1979b). My possible disagreement with Cronk in this matter is based on the observation that no societies, not even those of hunters and gatherers, are devoid of conceptions, often religious and always moral, encouraging their members to act in ways that are counter to their material and reproductive self-interests. Since conceptions of this class are to be found universally and manipulative elites are not, Cronk's manipulative interpretation, as I argued earlier but reiterate here, cannot be taken to be more than an account of how such conceptions may be used in societies in which such elites do exist.

Two possible counterarguments can, I think, be dismissed. First, it can be claimed that so-called egalitarian societies are not really egalitarian. Australian men, for instance, surely do subordinate Australian women and this subordination is sanctified by religious conceptions and practices. But it is the men, not the women, who are required by these conceptions to undergo such health-endangering ordeals as circumcision and subincision. Second, and related, it could also be argued, rather crudely, in my view, that the brighter members of egaliatrian societies espouse selfless conceptions but leave it to their duller companions to act upon them. It cannot be denied that this sort of thing goes on, but it would be, at the least, difficult to demonstrate that it is sufficiently prevalent to allow us to characterize the religious and moral discourse that it exploits as essentially duplicitous. More decisive, in some instances it is clear that such a manipulative view doesn't fit the facts. Whatever rewards their society has to offer Australian Aboriginal men-prestige, knowledge, access to women-are available only to those who have gone through the ordeals.

It is, in sum, a mistake to account for the religious and moral conceptions in the possession of humans as mere instruments 
manipulated by special or individual interest to exploit others. They are better seen to be in the service of community against the selfish interests of the separate individuals who make it up (in all three senses of "make it up"). We may recall here Henri Bergson's $(1935,112)$ characterization of religion as society's defense against "the dissolvant power of [individual] intelligence." This view, which proposes that society is distinct from, but not separated from, the individuals making it up, is difficult for evolutionary biological theories to accommodate. This, I think, is their fundamental limitation.

\section{Human Language AND THE Evolution OF MORALITY}

The emergence of language has not only brought new things, like gods, honor, and truth into the world, but it has also, I have implicitly argued, transformed the nature of adaptive systems. I take the term "adaptation" to designate the processes through which living systems maintain themselves, in the face of ceaseless perturbations threatening to disrupt them, through more or less continuous reversible changes of state and more or less discontinuous and irreversible changes in structure. Gregory Bateson (1972) put the matter into informational terms by proposing that adaptive systems are entities that attempt to maintain the truth value of certain propositions about themselves in the face of perturbations threatening to falsify them. In biotic systems, such "propositions" are systems of interrelated physiological, genetic, and ecological variables-body temperature, blood pressure, reproduction rates, primary productivity, and so on-but in cultural systems, regnant propositions are propositions properly so-called, like "The Lord our God, the Lord is One."

If we understand adapting entities as systems of information, we must recognize that, among humans, these systems include symbolic as well as physiological and genetic information. Whereas the biotic elements of such systems are fundamental-without them there is nothing-it seems that the symbolic components have become increasingly dominant. These elements are not, in the main, representations of biotic elements nor are they necessarily in the service of those elements' preservation or reproduction. They do not, this is to say, necessarily act to maintain the truth value of the biotic "propositions" upon which their own persistence is dependent and may even threaten to falsify them. Nuclear weapons, ozone depletion, excessive $\mathrm{CO}_{2}$ emissions, oceanic pollution are all products of symbolically informed action. Although it may be in someone's 
special economic or political interest to generate them, they don't, so far as I know, do anything good for anyone's health.

Religion and its moral pronouncements can, as Cronk and I agree, be captured by and come to serve such special interests, but to recognize religion's vulnerability is not to agree that it is, in its essence, in the service of such interests. At the same time that some religions have sanctified oppression and colonialism, others-for instance, movements guided by liberation theology and revitalization movements throughout history-have ever again risen up against such oppression. More fundamentally, religion has, at least until recently, grounded all of the conventional, which is to say the specifically human, elements of the world, and it is not clear that anything that can replace it has yet emerged.

It is possible that the world would be safer if human understandings, institutions, and actions could really be accounted for by evolutionary biology (despite what I take to be evolutionary biology's simpleminded and ugly view of human nature), for if this were so, culture could not endanger biological survival. As it stands, however, the abiding and perhaps irreducible contradiction between the symbolic and biotic information constituting human systems-a contradiction unique to humanity which evolutionary biology, because of its very nature, may not be able to recognize - may be the deepest, most dangerous, and most difficult problem facing not only our species but the world which our species is increasingly able to destroy.

\section{NOTE}

I am grateful to Meryl Mann Cohen for many helpful suggestions during the preparation of this response.

\section{REFERENCES}

Alexander, Richard. 1985. "A Biological Interpretation of Moral Systems." Zygon: Journal of Religion and Science 20 (March): 3-20.

Austin, J. L. 1962. How to Do Things with Words. Oxford: Oxford Univ. Press.

Bateson, Gregory. 1951. "Conventions of Communication: Where Validity Depends upon Belief." In Communication: The Social Matrix of Psychiatry, edited by J. Ruesch and G. Bateson, 217-27. New York: Norton.

. 1972. "Cybernetic Explanation." In Steps to an Ecology of Mind, 399-410. New York: Ballantine.

Bergson, Henri. 1935. The Two Sources of Morality and Religion. New York: Henry Holt.

Buber, Martin. 1952. Good and Evil: Two Interpretations. New York: Charles Scribner's Sons.

Campbell, D.T. 1991. “A Naturalistic Theory of Archaic Moral Orders.” Zygon: Journal of Religion and Science 26 (March): 91-114.

Dawkins, R., and J.R. Krebs. 1978. "Animal Signals: Information or Manipulation?" In Behavioral Ecology: An Evolutionary Approach, 1st ed., edited by J. R. and N. B. Davies, 282-309. Oxford: Blackwell Scientific. 
Harper, D.G.C. 1991. "Communication." In Behavioral Ecology: An Evolutionary Approach, 1st ed., edited by J.R. and N.B. Davies, 374-97. Oxford: Blackwell Scientific.

Marshall, J. C. 1970. "The Biology of Communication." In Man and Animals in New Horizons in Linguistics. Harmondsworth, England: Penguin.

Peirce, Charles Sanders. 1960. Collected Papers of Charles Sanders Peirce. Vol. 2, Elements of Logic, edited by Charles Hartshorne and Paul Weiss. Cambridge: Harvard Univ. Press.

Rappaport, Roy. 1979a. "The Obvious Aspects of Ritual." In Ecology, Meaning and Religion. 173-222. Berkeley: North Atlantic Books.

. 1979b. "Sanctity and Lies in Evolution." In Ecology, Meaning and Religion, 223-46. Berkeley: North Atlantic Books.

. 1984. Pigs for the Ancestors, new enlarged edition. New Haven: Yale Univ. Press.

27 (March): 5-30.

Searle, J.R. 1969. Speech Acts. Cambridge: Cambridge Univ. Press.

Wallace, Anthony F.C. 1966. Religion: An Anthropological View. New York: Random House. 